University of Wollongong

Research Online

Faculty of Business - Papers (Archive)

Faculty of Business and Law

2018

Designing a knowledge management system for social services not-forprofit organisations

Peter R. Massingham

University of Wollongong, peterm@uow.edu.au

Rada Massingham

Western Sydney University, rkm722@uowmail.edu.au

Alan A. Pomering

University of Wollongong, alanp@uow.edu.au

Follow this and additional works at: https://ro.uow.edu.au/buspapers

Part of the Business Commons

Research Online is the open access institutional repository for the University of Wollongong. For further information contact the UOW Library: research-pubs@uow.edu.au 


\title{
Designing a knowledge management system for social services not-for-profit organisations
}

\author{
Abstract \\ This article discusses knowledge management system design for SSNFPOs. The transfer of best practice \\ knowledge management to SSNFPOs is not easy. SSNFPOs have different strategies and ways of doing \\ business compared to 'for-profit' organisations. Sector reforms in disability services, aged care, and child \\ services in Australia threaten to disrupt social value as new for-profit rivals enter and pursue economic \\ value. In response, the case study organisation (CSO) has been working with the research team to \\ consider how knowledge management might help it become a stronger organisation and ensure its \\ survival and growth in the reformed sector. The research was informed by discussions involving the CSO's \\ management and the research team over an 18 month period. A general framework for designing \\ knowledge management for SSNFPOs was developed. It involves six theoretical platforms, along with \\ problems associated with theory and practice, how knowledge management may address these \\ problems, and measures of impact. \\ Disciplines \\ Business

\section{Publication Details} \\ Massingham, P., Massingham, R. \& Pomering, A. (2018). Designing a knowledge management system for \\ social services not-for-profit organisations. International Journal of Knowledge Management, 14 (3), \\ 69-81.
}




\title{
Designing a Knowledge Management System for Social Services Not- For-Profit Organisations
}

\author{
Peter Massingham, University of Wollongong, Wollongong, Australia \\ Rada Massingham, Western Sydney University, Campbelltown, Australia \\ Alan Pomering, University of Wollongong, Wollongong, Australia
}

\begin{abstract}
This article discusses knowledge management system design for SSNFPOs. The transfer of best practice knowledge management to SSNFPOs is not easy. SSNFPOs have different strategies and ways of doing business compared to 'for-profit' organisations. Sector reforms in disability services, aged care, and child services in Australia threaten to disrupt social value as new for-profit rivals enter and pursue economic value. In response, the case study organisation (CSO) has been working with the research team to consider how knowledge management might help it become a stronger organisation and ensure its survival and growth in the reformed sector. The research was informed by discussions involving the CSO's management and the research team over an 18 month period. A general framework for designing knowledge management for SSNFPOs was developed. It involves six theoretical platforms, along with problems associated with theory and practice, how knowledge management may address these problems, and measures of impact.
\end{abstract}

\section{KEYWORDS}

Knowledge Management System Design, Knowledge Management, Not-For-Profit Organisations, Social Care Services

\section{INTRODUCTION}

This paper examines the design of a knowledge management (KM) system in a social service, not-forprofit organisation (SSNFPO) in Australia. Previous research has found that SSNFPOs often develop their own definitions of what KM means for their organisation and adopt a customised approach (Hume and Hume, 2008). The interesting challenge in designing a KM system for SSNFPOs is the difference in strategy between them and for-profit organisations (Bontis and Serenko, 2009). Whereas for-profits see KM as the cause of inter-firm differences in performance and profitability (e.g. see Mouritsen et al., 2001)., social enterprises see KM as helping achieve additional organisational priorities, particularly the sharing of best practice, advancing the body of knowledge associated with better quality social care, and societal benefits (e.g. see Guldberg et al., 2013). SSNFPOs are also increasingly trying to corporatize; which is being driven by changes in the hybridity of their mission, requiring them to be accountable to deliver both financial and social results (Battilana and Lee, 2014). This paper will present conceptual ideas about the impact of these changes on SSNFPOs' $\mathrm{KM}$ in terms of their strategy and implementation. 
SSNFPOs are organisations that tackle social problems, improve communities, people's life chances, or the environment (Granados et al., 2017). There is an increasing need for more research to understand the characteristics of these organizations and the different strategies used to maximise their social and environmental impact (Granados et al., 2017). Research has revealed that social enterprises have a multi-bottom line covering economic, environmental and social goals; a multiple stakeholder dimension; and a broad financial perspective to focus on sustainability (Villeneuve-Smith, 2011). However, this creates tension between social and economic missions which SSNFPOs have addressed with unique values, identity, resource allocation, decision-making and management of capabilities (Stevens et al., 2015). Their approach to value creation focuses on sustainable solutions rather than sustainable advantages; which they try to do by empowering others (internally and externally), as opposed to the more traditional approach of scientific management (compliance and control) (Santos, 2012).

SSNFPOs, therefore, present a different way of doing business. Distinguishing characteristics of charities, for example, include staffing profile (more volunteers than paid workers) and their sources of revenue (more donation than fee-based) (Kilbourne and Marshall, 2005). This makes them vulnerable to economic cycles, and also less able to invest in knowledge management (Greenaway and Vuong, 2010). Directly applying for-profit KM principles to the SSNFPO context is not easy (Hume et al., 2012), and not necessarily appropriate. Failing to address these differences may adversely affect theory and practice (Greenaway and Vuong, 2010). Previous research has found that social enterprise KM often focuses on developing a sense of community, e.g. connecting teams with others who have faced similar tasks or projects; and less on technology or strategy (Ragsdell et al., 2014). Social enterprises rely upon the experience and skills of their staff and volunteers to deliver their services or products rather than tangible assets, such as technology (Lettieri et al., 2004). That KM system design for SSNFPOs, therefore, may require a person-centred approach to KM. These issues are explored in an exploratory case study which develops conceptual ideas surrounding KM design for not-for-profit organisations. The paper continues with a brief literature review; followed by the study context - case study organisation, problem conceptualisation, and methodology; then the results and discussion; and a conclusion.

\section{OVERVIEW OF KNOWLEDGE MANAGEMENT}

Knowledge management (KM) may be defined as combining organizational and technical solutions to achieve the goals of knowledge retention and reuse in order to improve individual and organizational learning (Jennex, 2007). KM system design may be distinguished in terms of strategy and implementation. Strategy focuses on KM goals and its value for organizations. The goals for KM are to "identify critical organizational knowledge assets, acquire those assets in an accessible repository, establish mechanisms for sharing the assets among organizational workers, apply the appropriate knowledge to specific decision domains, determine the effectiveness of knowledge application, and adjust knowledge artifacts to improve their effectiveness" (Jennex et al., 2016). The difference in strategy between for-profits and SSNFPOs means that their knowledge requirements may differ Greenaway and Vuong, (2010). For example, charities may focus on volunteers' "miscellaneous knowledge" (Lettieri et al., 2004, p. 25) while for-profit firms may focus on declarative, procedural or causal knowledge (Zack, 1999). Therefore, SSNFPOs' KM goals may differ in terms of critical knowledge assets, which will then influence the other KM goals.

Organizations create KM systems to support their KM initiatives (Jennex et al., 2016). Implementation is improved by KM system design that enables knowledge workers to access its organizational memory (i.e. structural capital), and to use that knowledge to create value for the organisation. Organisational memory is particularly important in SSNFPOs. For example, volunteer turnover in charities create organizational memory loss which may cause repeat mistakes (Greenaway and Vuong, 2010). KM implementation may create value by improving processes and procedures, 
better application of knowledge across functional areas, and better business performance (Jennex et al., 2016). KM initiatives may address specific problems for SSNFPOs, such as knowledge loss, through retention, creating and acquiring new knowledge, and improving the connections between paid staff (Greenaway and Vuong, 2010).

SSNFPOs typically have limited finances which constrains their ability to invest in KMS (Greenaway and Vuong, 2010). Therefore, KM systems need to be carefully designed and implemented with a clear view of what constitutes success to ensure that SSNFPOs receive a satisfactory return on their investment. Jennex et al., (2016) argue the importance measuring KM performance in terms of processes and outcomes critical success factors (CSFs). These may be included in KM system design by integrating knowledge into organizational processes; and also used as key performance indicators (KPIs) for assessing the outcomes associated with KM initiatives (Jennex et al., 2016). However, assessing organizational performance is a challenge for SSNFPOs, as value is outcomes-focused, i.e. service delivery, and not financially-focused (Hatry, 2007).

\section{THE CASE STUDY ORGANISATION}

The organisation chosen for this case study is an Australian SSNFPO. The SSNFPO is a registered charity and social enterprise which provides services for disadvantaged communities, including aged care. The case study organisation (CSO) is operating in a changing and increasingly competitive marketplace. Aged care in Australia is undergoing reforms to ensure the system can be sustainable and affordable (https://agedcare.health.gov.au). The main changes are the introduction of a single quality framework and a move towards consumer-directed care. The reforms aim to give people greater choice, recognising most people want to stay independent, and care will be based on needs and flexibility. In response, the CSO has been working with the research team to consider how knowledge management might help it become a stronger organisation and ensure its survival and growth in the reformed sector.

\section{PROBLEM CONCEPTUALISATION}

The main problem in designing implementation for the CSO's KM system is debate over what constitutes social care knowledge. The knowledge of social care may be described in terms of three inter-related types: theoretical knowledge (from study and research), factual knowledge (about the client or case), and practice knowledge (about how to deliver care or services effectively (Trevithick, 2008). However, there is debate about which knowledge is more valuable, and how to manage these resources to arrive at a decision about practice (Trevithick, 2008). Social service involving healthcare, such as aged care, tends to focus on clinical governance, which integrates the activities which may impact patient care (Bloice and Burnett, 2016).

KM system implementation may deliver value for the CSO by (a) developing social capital leading to differentiation as a SSNFPO; (b) designing a structure and culture which ensures improved decision making, collective ways of thinking, and positive work behaviours, e.g. teamwork, cooperation, collaboration; and (c) reducing cost and improving work performance by standardising best practice (particularly back office) and (d) embedding knowledge management into high value creating activities to improve operational efficiency.

\section{METHODOLOGY}

This study adopted an action research (AR) methodology. AR is now a well-documented and wellaccepted research methodology (Hearn et al. 2008; Massingham, 2015). AR is applied research in which the primary goal is to facilitate social change or bring about value oriented political-social goal 
(Neuman 2006, p. 28). The researchers worked with practitioners to design a knowledge management system that would improve the SSNFPO's performance and service delivery. The method involved regular interaction between an expert(s) and an analyst(s); where the expert was the SSNFPO practitioners and the analyst was the researchers.

Gavrilova and Andreeva, (2012) distinguish 'passive' and 'active' methods from the perspective of the level of involvement of an analyst as compared to the efforts of an expert. Three categories of methods are identified: (1) active (analyst-leading) where the analyst elicits knowledge from the expert with specially prepared questions (e.g. survey research); (2) passive (expert-leading) where the expert is highly engaged and the analyst's involvement is very limited (e.g. observation/listening followed by analysis); (3) active-passive where the expert and analyst work closely together as partners to find solutions (e.g. research interventions) (Gavrilova and Andreeva, 2012).

The study used expert-leading collective methods (i.e. passive). Collective methods include round-table and brainstorming. This study combined both methods. The round-table method involves discussion of a topic by a number of experts (typically three to seven), each given equal opportunity to engage, which helps achieve action research's goals of democracy and participation. The brainstorming method facilitates new ideas, without critique, in order to stimulate creative thinking, (Gavrilova and Andreeva, 2012). The study used brainstorming in a round-table setting to allow the SSNFPO practitioners to explore their understanding of knowledge management and what it might offer their organisation. The researchers adopted a passive role by providing information on current best practice and contributing answers to questions when required. This was done intentionally to engage the practitioners in the discussion and to respect the fact that SSNFPOs have a different way of doing business compared with for-profits. In this way, the passive round-table brainstorming method enabled the researchers to create new ideas about knowledge management within a SSNFPO setting by allowing the practitioners to work out for themselves how knowledge management could work for them. The outcome of 18 months of these discussions is summarised in this paper.

The discussions led to the following results, discussion and conceptual outcomes (Figure 1) in this way. First, we sought to understand what was driving the SSNFPO's (case study organisation) interest in KM. The discussions revealed a desire to corporatize and embrace best practice associated with for-profits. The forces for change were a need to increase customer value while also managing costs. At this point, the dualistic strategies of social responsibility and cost reduction emerged. Second, we discussed how KM might help the SSNFPO achieve this dual strategy. These conversations revealed barriers to change including problems with culture, governance, and productivity; as well as an aversion to competition. Third, we examined how KM might address these issues and help implement the strategy.

\section{RESULTS AND DISCUSSION}

\section{Social Responsibility}

The contemporary move toward marketing sustainability is driven by clients no longer choosing brands on functional and emotional grounds only, but also on how companies meet their social responsibilities (Pomering, 2017). This has increased the complexity of marketing strategy necessary to ensure the creation of economic value and also social value (Layton, 2016).

SSNFPOs are focused on their clients and the desire to provide quality social care drives every part of their business model. However, the hybrid mission of SSNFPOs highlights fundamental differences in approach to marketing between them and for-profit organisations. The tension emerges because SSNFPOs do not focus much on economic value, e.g. profit, and instead interpret marketing as creating social value. They also do not focus on the competitive aspects of the marketing mix, i.e. persuading clients to choose them instead of rivals. They tend to assume their clients need them, and focus on service delivery, i.e. how to give them quality care. 
The role of KM is to help the CSO implement its social responsibility marketing strategy within its changing market environment. The first step was to persuade the CSO that it needed to focus more on economic value. This was a KM issue because it involved increasing the CSO's knowledge of the changing external environment. This knowledge required the CSO to really understand their clients. The Government's reform agenda aimed to give clients more choice and flexibility. This empowerment of vulnerable people meant the CSO could no longer rely upon attracting clients simply because they needed social care. The CSO would need to compete for clients. This introduced two opportunities for KM to have impact. The first opportunity is market intelligence. This aligns with previous research on the role of knowledge management in marketing (e.g., Darroch \& McNaughton, 2002), which focus on knowledge as informing decision-makers when making choices associated with marketing strategy. The impact is to use KM to gather useful information about the value proposition offered by the CSO and clients' buying behaviour. This is about knowledge as a resource. The second opportunity is to use this information to design co-creation of value for clients. The CSO needed to develop marketing professionals able to manage the cognitive processes associated with the broader strategy, structure, and culture of their organization to help them find meaning, and make good marketing mix decisions. This is about KM as a capability.

The second step was to develop consensus about the corporate identity of the CSO with social responsibility as their marketing strategy. This was a KM issue because it involved developing shared mental models and learning about the hybrid strategy of economic and social value. Previous research has not adequately addressed contemporary views of marketing within SSNFPOs as professional practice. This involves cognitive processes of problem-framing and problem-solving based on the individual's theory of practice. The changing market will create confusion about strategy and roles amongst the CSO staff. KM's role is to examine the judgment, i.e. cognitive skills, necessary for handling complexity, uncertainty, and value-conflict when engaging people and problems associated with a new hybrid marketing strategy. It enables the CSO to develop internal marketing capability (e.g. see Hume and Hume, 2015).

\section{Competitive Advantage}

The knowledge economy is a concept developed by Bell (1973) and popularized by Drucker (1988, 1999) which explains how knowledge is the main driver of economic value. SSNFPOs focus on social value (Santos, 2012) may, therefore, may be cynical about the claims made by KM, particularly about how it creates economic value.

The role of KM is to help the CSO understand the value of its knowledge resources and how KM may help it compete in a changing market environment e.g. the introduction of for-profit rivals. The first step is to identify valuable resources. It is important to assess how knowledge affects activities which may impact on patient care (Bloice and Burnett, 2016). The solution is to combine the VRIN criteria for sustainable competitive advantage with the knowledge accounts model (Massingham, 2016) to measure the value of the CSO's knowledge resources against the three social care dimensions e.g. theoretical knowledge, factual knowledge, and practice knowledge. The VRIN criteria is four tests of competitive power: is the resource or capability competitively valuable, rare - something rivals lack, hard to copy-inimitable, invulnerable to the threat of substitution-non-substitutable (Thompson et al, 2016).

The second step is to help the CSO see the value of knowledge management. This means addressing the three main criticisms of KM: (1) knowledge cannot be separated from the knower, (2) KM is too difficult, and (3) lack of evidence between KM and organizational performance (Massingham, 2016). The way to address these concerns for SSNFPOs is to explain how KM is the next step in the gap left by evidence-informed practice (Lee and Austin, 2012). This gap is how theoretical knowledge, e.g. KM best practice, might combine with experiential knowledge, evidence-informed practice, to develop new knowledge. The focus is to explain how KM contributes to the CSO's social care. 


\section{Cultural Change}

As stated earlier, one of the goals of KM is to improve individual and organizational learning (Jennex, 2007). Organisational learning creates value by increasing knowledge resources, generating creativity and innovation, continuous improvement, and enabling skilful knowing at the individual, group, and organisational levels. Views about learning are presented by the fields of behaviourism, cognitive psychology, and social constructivism. There are different perspectives about how organisational culture may improve learning. Behaviourism is based on stimulus-response models (Gutherie, 1935). It is about reward and recognition. Cognitive psychology sees learning as changes in states of knowledge (Bruner et al, 1956). It is about intrinsic rewards and self-led teams. Social constructivism sees learning as easier to do by observing and interacting with others (Bandura, 1977). It is about social capital.

The learning organisation is an aspirational business model describing an entity that learns from experience, responds to change, and grows its knowledge resources (Massingham and Diment, 2009). Previous research has found that SSNFPOs use KM to develop a sense of community (Ragsdell, et al., 2014), and they rely upon the experience and skills of their staff to deliver their services (Lettieri et al., 2004). However, SSNFPOs may reject the learning organisation if they have a compliancebased culture. This rejection may occur due to the culture generating risk avoidance behaviour and dependence on clinical governance. These factors represent barriers to the learning organisation principles of empowerment, creativity, and innovation. Compliance-based cultures require people to follow the rules rather than challenge them.

The role of KM is to examine whether the learning organisation can be implemented by cultural change, and deliver the benefits it promises in terms of positive work behaviours e.g. teamwork, collaboration, and cooperation, and improved organizational learning. The first step is to examine the CSO's existing culture in terms of behaviourism, cognitive psychology, and social constructivism to establish alignment with learning organization characteristics. The second step is to design and implement strategies to improve the CSO's learning organisation performance. The CSO is a compliance-based organisation. It wants to change to become an employee-led organisation. This requires cultural change focused on empowering employees. However, this is difficult within the context of the nature of their work. Social care carries great responsibility, particularly when dealing with vulnerable clients, and the consequences of mistakes are serious. The tension between compliance and empowerment may be resolved by using the learning organisation to introduce cultural change designed to improve employees' emotional relationship with the organisation.

\section{Performance Improvement}

The codification and personalization views of KM provide contrasting ideas about how KM may improve performance. The codification view proposes that the unskilful individual will use information technology to identify and then use knowledge which has been captured by their organization to help them become skilful (e.g. see Kearns and Lederer 2003). The personalization view of KM proposes that this individual will work it out for themselves, i.e. learn by doing, or seek help from others (Gardner, 2012). Researchers have recognised the shift from technology (codification) towards socialization (personalization) (e.g. see Berry, 2015).

The shift towards the personalisation view of KM should suit SSNFPOs because they want to empower staff. However, this approach can be inefficient because of lost productivity while employees take time to become skilful knowers. SSNFPO staff are often very good at their jobs. However, staff may also be working in jobs that require relatively low skill levels with low pay. As a result, staff tend to follow the rules as they are neither suitably skilled or paid to take responsibility for creating new practices. The changing nature of the CSO's market means that it will need to improve its performance if it is to survive competition from new for-profit rivals. This creates a tension between the inefficiency in the personalisation approach and the need for improved performance. Staff will be empowered to discover new practices, which will challenge them to learn new knowledge, which will take time. This study distinguished between complex tasks requiring tacit knowledge, and routine tasks requiring technical knowledge (Nonaka and Takeuchi, 1995). This recognises that there are 
tasks which may be standardised and done by following best practice (routine), and those that are context-specific and may be achieved via multiple best practices (complex). Routine tasks are covered in the next section on cost reduction. The inefficiencies in complex tasks were addressed by process centred knowledge management.

The role of KM is to use lean thinking to explore how skillful knowing will reduce or eliminate waste and increase efficiency in work flow. It assumes that unskillful knowing creates waste because the individual lacks know-what or know-how knowledge (e.g. see Edmondson et al., 2003), and this causes delays. KM may improve efficiency within the process by enabling skillful knowing in minimum time. The first step is to identify problem processes. These are complex tasks at the CSO where there is an unsatisfactory level of employees with unskillful knowing. The context-specific nature of these tasks means that transferring a single best practice, e.g. by staff training, is ineffective. Therefore, each problem process has to be examined individually. The second step is to examine why these tasks have waste points using process centred knowledge management's view of the operational core of knowledge: workflow execution, information processing, motivation, and decision making (Raghu and Vinze, 2007); within the context of the tasks in performing a business process. This identifies the nature of the waste point. Complex tasks have waste points due to learning by doing time. The situational context, i.e. multiple best practices, means that staff cannot rely upon codified knowledge as in routine tasks, and often have to work it out for themselves or apply tacit knowledge from others to their situation. The third step is to design KM solutions and embed them into the problem process (Massingham, and Al-Holaibi, 2017). The appropriate KM solution is determined by the nature of the waste point (step 2) and is then situated within the task as a core activity (Massingham, and Al-Holaibi, 2017), so that individuals capture and use knowledge as part of their normal work (Han and Park, 2009).

\section{Cost Reduction}

KM may reduce costs by capturing best practice and sharing this knowledge to improve efficiency. This efficiency is generated by increased productivity as staff spend less time learning by doing, searching for knowledge, and rectifying mistakes or poor-quality work. Process management is typically used by organisations to improve performance, including productivity (Becerra-Fernandez and Sabherwal, 2010). KM contributes to process management via systems, technologies and tools which enable knowledge to be captured, stored, and shared to benefit the organization (BecerraFernandez and Sabherwal, 2010). Workflow management systems (WMS) are a tool typically used for back-office integration processes (van der Aalst and Van Hee, 2002). WMS maps processes and implements best practices. WMS is most effective in work that is routine and standardized. Therefore, it suits work that benefits from specialization of task in the sense that repetition leads to improvement and refinement and, eventually, a single best practice.

The role KM is to use process centred knowledge management for routine tasks requiring codified knowledge at the act of doing. It assumes that unskillful knowing creates waste due to unproductive work e.g. high supervision costs, redoing unsatisfactory work, fixing mistakes. These sunk salary costs may be significant due to the high volume of routine tasks. KM may reduce costs by reducing waste in routine tasks. It does this in two ways. The first step is to identify, capture, store, and share best practice. The second step is to ensure best practice is maintained by using IT for facilitated collaboration. The CSO felt that IT was the best way to collaborate in routine tasks. Recent research explained that 'the main role of new information and communication technologies (ICTs), such as Web 2.0/3.0, collaborative technologies 2.0, social networking tools, wikis, internal blogging, is to help people share knowledge through common platforms and electronic storage' (Soto-Acosta and Cegarra-Navarro, 2016: 417). The term KM 2.0 has been coined to describe the acquisition, creation and sharing of collective intelligence through social networks and communities of knowledge (Sigala and Chalkiti, 2014). KM may facilitate collaboration via KM 2.0 concepts to efficiently capture best practice in routine tasks, and maintain their currency (i.e. update). The outcome is that employees have access to codified knowledge necessary to complete routine tasks in the act of doing. 


\section{Risk Management}

Organizational risk management is typically based on decision tree models, i.e. measuring the likelihood and consequences of the risk event (De Zoysa and Russell, 2003). However, this approach may be ineffective due to complexity and cognitive constraints (Massingham, 2010). SSNFPOs have a different perspective on risk compared with for-profits. Rather than focusing on risks associated with economic value, SSNFPOs focus on risks to social value. This presents complex challenges for the CSO due to its dependence on employees to deliver social value to clients and the nature of social care. Employees create risk due to variability in their human capital. The same issues which represented barriers to knowledge flow in complex tasks outlined in the section on performance improvement, i.e. workflow execution, information processing, motivation, and decision making - also pose risks. The nature of the knowledge necessary to deliver social care, i.e. - theoretical knowledge, factual knowledge, and practice knowledge (see section on competitive advantage) - also poses risk. This risk may involve the nature of the knowledge itself, i.e. its tacitness or complexity, which make it difficult to share (Massingham, 2010), the loss of valuable knowledge (Massingham, 2018), and the difficulty in managing the threat to capability (Massingham, 2010).

The role of KM is to improve objectivity and cognitive clarity in risk management associated with managing complex tasks (Massingham, 2010). KM can address the complexity of risk at the CSO, in terms of knowledge loss, in three steps: risk event, risk exposure and risk response (Massingham, 2010). This has been proved to address the underlying problems with traditional decision tree models by focusing risk assessment on the knowledge necessary to manage the risk event, rather than the activity (Massingham, 2010). The steps involve identifies the risk event (risk associated with losing knowledge in important activities); the level of exposure (likelihood and consequences of the risk occurring), and the risk response (capacity to fill the gap). The outcome is risk management which addresses the cognitive bias (subjectivity) and complexity (environmental uncertainty) inherent in decision tree models.

\section{Research Implications and Recommendations}

Figure 1 is a general framework for KM for SSNFPOs. The problem conceptualisation was derived from the action research with the CSO and framed within the findings from the literature review. The research questions emerged from the problem conceptualisation to verify the CSO's interpretation of the evidence for practice. The KM implementation directly addresses the problems and the research questions. The outcomes defined the value of the KM system's strategy (purpose) and implementation (practice) within the context of clinical governance.

Figure 1 begins with the theoretical platform explored by this paper. The framework was developed in response to discussions with the CSO about how KM might help it corporatize. The CSO was somewhat sceptical about the nature of the ideas presented by KM, particularly whether best practice used in for-profits would be transferable to the different environment of SSNFPOs. The theory selected (see left hand-side of Figure 1) emerged from these discussions in the sense that these six topics were the main issues facing the CSO and how KM might help and, therefore, persuade the CSO that it has value. The problem identification recognises the different nature of doing business for SSNFPOs compared with for-profits. It also highlights how simply transferring best practice KM based on forprofits is difficult. As we move across Figure 1, evidence for practice explains the challenges KM faces in persuading SSNFPOs that it has value. KM's role summarises how it can help SSNFPOs. Strategy explains the purpose necessary for KM system design; while implementation explains its practice. The financial and non-financial impact measure the outcomes SSNFPOs may expect from this KM system design (e.g. see Jennex \& Olfman, 2005). The causal relationships in the framework are explained by the arrows on the right-hand side of Figure 1. The first three constructs (rows) combine to grow the top line (i.e. increase revenues) via value, differentiation, and productivity. The bottom three constructs (rows) combine to manage the bottom line (i.e. reduce costs) via productivity, performance improvement, and governance. 


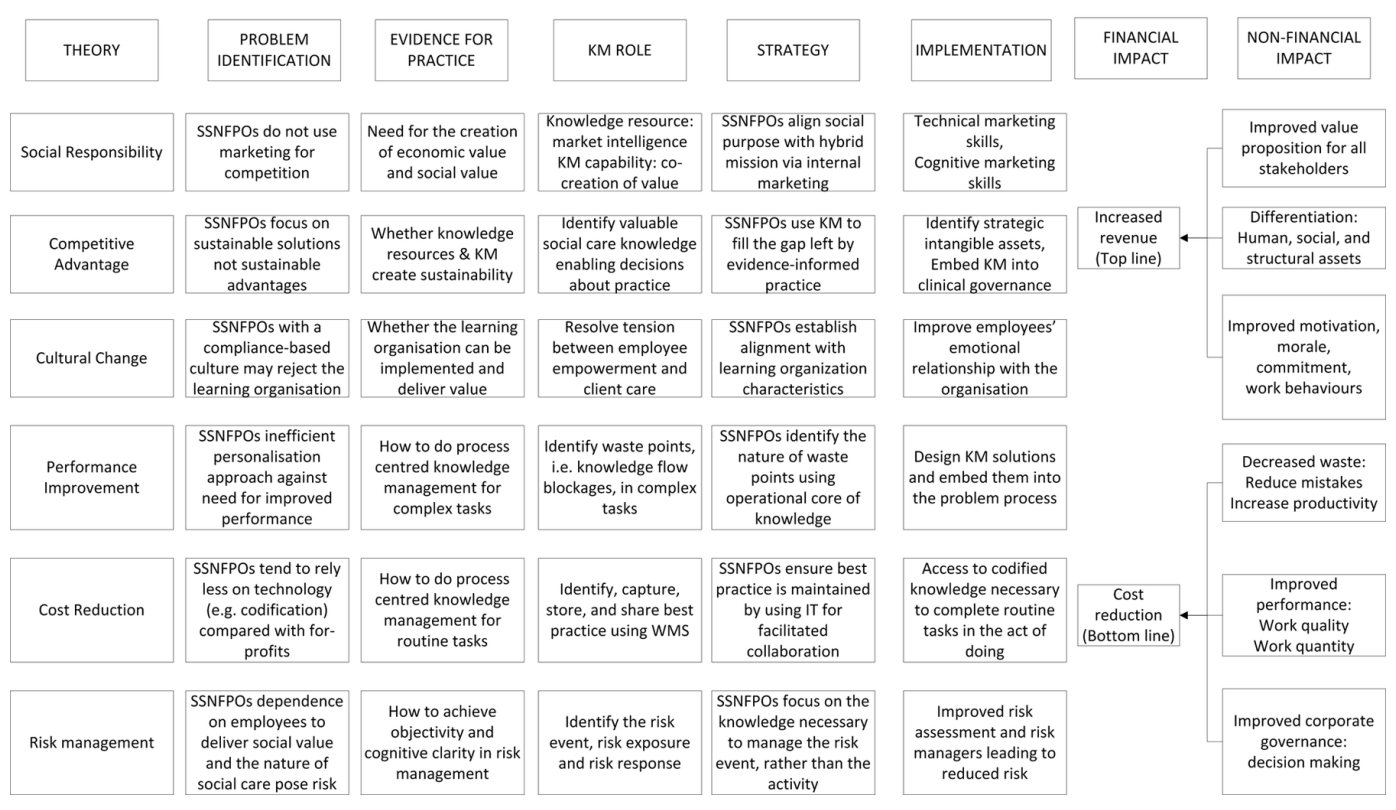

\section{CONCLUSION}

The paper set out to examine the design of a knowledge management (KM) system in a social service not-for-profit organisation (SSNFPO). An underlying assumption is that SSNFPOs are different from for-profit firms, and this should be taken into account in KM system design. The KM strategy is influenced by the focus on social value rather than economic value. The KM implementation is influenced by the nature of social care and the knowledge resources necessary to deliver this service. The paper has developed ideas about KM systems for SSNFPOs trying to corporatize in response to increased competition from for-profits. SSNFPOs' limited capacity to invest in KM, emphasises the importance of adopting best practices from other SSNFPOs, rather than trying to retrofit models designed for other purposes (Greenaway and Vuong, 2010). SSNFPOs have remarkable abilities to learn from others (Greenaway and Vuong, 2010). This paper provides a platform for future research about KM system design for SSNFPOs leading to greater long term sector capacity.

The paper recognises that SSNFPOs are different from for-profits, and KM system design must adapt to their way of doing business. The paper has proposed that KM design is grounded in six theoretical domains. KM practice should address the problems identified for the CSO. KM implementation needs to adapt KM best practice to the SSNFPO business model necessary to achieve the hybrid mission, i.e. both economic and social value. Outcomes need to deliver practical benefits within the context of clinical governance and the unique nature of social care knowledge resources. This research was a qualitative study that was conducted at one SSNFPO, and the system proposed has not yet been empirically tested. It may be applicable to a type of SSNFPO, rather than all SSNFPOs, i.e. those that resemble the characteristics of the CSO. However, we hope that all SSNFPOs might learn something from the system which they might apply to their organisational context. There are exciting opportunities to test the ideas presented in this paper with other SSNFPOs. 


\section{REFERENCES}

Bandura, A. (1977). Social Learning Theory. London: Prentice-Hall.

Becerra-Fernandez, I., \& Sabherwal, R. (2010). Knowledge Management: Systems and Processes. Armonk, NY: M.E. Sharpe.

Bell, D. (1973). The Coming of Post-Industrial Society, Hammondsworth. Penguin.

Berry, H. (2015). Knowledge inheritance in global industries: The impact of parent firm knowledge on the performance of foreign subsidiaries. Academy of Management Journal, 58(5), 1438-1458. doi:10.5465/ amj.2013.0724

Bloice, L., \& Burnett, S. (2016). Barriers to knowledge sharing in third sector social care: A case study. Journal of Knowledge Management, 20(1), 125-145. doi:10.1108/JKM-12-2014-0495

Bontis, N., \& Serenko, A. (2009). A causal model of human capital antecedents and consequents in the financial services industry. Journal of Intellectual Capital, 10(1), 53-69. doi:10.1108/14691930910922897

Bruner, J. S., Goodnow, J. J., \& Austin, G. A. (1956). A Study of Thinking. New York: Wiley.

Darroch, J., \& McNaughton, R. (2002). Examining the link between knowledge management practices and types of innovation. Journal of Intellectual Capital, 3(3), 210-222. doi:10.1108/14691930210435570

De Zoysa, S., \& Russell, A. D. (2003). Knowledge-based risk identification in infrastructure projects. Canadian Journal of Civil Engineering, 30(3), 511-522. doi:10.1139/103-001

Drucker, P. (1999). Knowledge-worker productivity: The biggest challenge. California Management Review, 41(2), 79-94. doi:10.2307/41165987

Drucker, P. F. (1988). The Coming of the New Organization. Harvard Business Review on Knowledge Management, (January).

Edmondson, A. C., Winslow, A. B., Bohmer, R. M. J., \& Pisano, G. P. (2003). Learning how and learning what: Effects of tacit and codified knowledge on performance improvement following technology adoption. Decision Sciences, 34(2), 197-223. doi:10.1111/1540-5915.02316

Eisenhardt, K. M., \& Graebner, M. E. (2007). Theory building from cases: Opportunities and challenges. Academy of Management Journal, 50(1), 25-32. doi:10.5465/amj.2007.24160888

Gardner, H. K. (2012). Performance Pressure as a Double-edged Sword: Enhancing Team Motivation but Undermining the Use of Team Knowledge. Administrative Science Quarterly, 57(1), 1-46. doi:10.1177/0001839212446454

Gavrilova, T., \& Andreeva, T. (2012). Knowledge elicitation techniques in a knowledge management context. Journal of Knowledge Management, 16(4), 523-537. doi:10.1108/13673271211246112

Gergen, M. M., \& Gergen, K. J. (2000). Qualitative inquiry: Tensions and transformations. In N. K. Denzin \& Y. S. Lincoln (Eds.), Handbook of Qualitative Research (2nd ed., pp. 1025-1046).

Gold, A. H., Malhotra, A., \& Segars, A. H. (2001). Knowledge management: An organizational capabilities perspective. Journal of Management Information Systems, 18(1), 185-214. doi:10.1080/07421222.2001.11045669

Granados, M. L., Mohamed, S., \& Hlupic, V. (2017). Knowledge management activities in social enterprises: Lessons for small and non-profit firms. Journal of Knowledge Management, 21(2), 376-396. doi:10.1108/ JKM-01-2016-0026

Greenaway, K. E., \& Vuong, D. C. H. (2010). Taking Charities Seriously: A Call for Focused Knowledge Management Research. International Journal of Knowledge Management, 6(4), 87-97. doi:10.4018/ jkm.2010100105

Guldberg, K. R., Mackness, J., Makriyannis, E., \& Tait, C. (2013). Knowledge management and value creation in a third sector organisation. Knowledge and Process Management, 20(3), 113-122. doi:10.1002/kpm.1410

Gutherie, E. R. (1935). The Psychology of Learning. New York: Harper and Row. 
Han, K. H., \& Park, J. W. (2009). Process-centered knowledge model and enterprise ontology for the development of knowledge management system. Expert Systems with Applications, 36(4), 7441-7447. doi:10.1016/j. eswa.2008.09.031

Hatry, H. P. (2007). Performance Measurement: Getting Results (2nd ed.). Washington, DC: Urban Institute.

Hearn, G., Tacchi, J. A., Foth, M., \& Lennie, J. (2009). Action Research and New Media: Concepts, Methods and Cases. Cresskill, NJ: Hampton Press.

Hume, C., Clarke, P., \& Hume, M. (2012). The role of knowledge management in the large non profit firm: Building a framework for KM success. International Journal of Organisational Behaviour, 17(3), 82-104.

Hume, C., \& Hume, M. (2015). The critical role of internal marketing in knowledge management in not-for-profit organizations. Journal of Nonprofit \& Public Sector Marketing, 27(1), 23-47. doi:10.1080/10495142.2014.934567

Jennex, M., \& Olfman, L. (2005). Assessing knowledge management success. International Journal of Knowledge Management, 1(2), 33-49. doi:10.4018/jkm.2005040104

Jennex, M., Smolnik, S., \& Croasdell, D. (2016). The Search for Knowledge Management Success. In 49th Hawaii International Conference on System Sciences (pp. 4202-4211). IEEE Computer Society.

Jennex, M. E. (2007). What is Knowledge Management? In M. E. Jennex (Ed.), Knowledge Management in Modern Organizations (pp. 1-9). Hershey, PA: IGI Global. doi:10.4018/978-1-59904-261-9.ch001

Kearns, G. S., \& Lederer, A. L. (2003). A Resource-Based View of Strategic IT Alignment: How Knowledge Sharing Creates Competitive Advantage. Decision Sciences, 34(2), 1-29. doi:10.1111/1540-5915.02289

Kilbourne, W. E., \& Marshall, K. P. (2005). The transfer of for profit marketing technology to the non-for-profit domain: From the theory of technology. Journal of Marketing Theory and Practice, 13(1), 14-25. doi:10.108 0/10696679.2005.11658535

Layton, R. (2016). There could be more to marketing than you might have thought! Australasian Journal of Marketing, 24(1), 2-7. doi:10.1016/j.ausmj.2016.02.001

Lee, C., \& Austin, M. J. (2012). Building organisational supports for knowledge sharing in county human service organisations: A cross-case analysis of works-in progress. Journal of Evidence-Based Social Work, 9(1/2), 3-18. doi:10.1080/15433714.2012.635473 PMID:22409608

Lettieri, E., Borga, F., \& Savoldelli, A. (2004). Knowledge management in non-profit organisations. Journal of Knowledge Management, 8(6), 16-30. doi:10.1108/13673270410567602

Lincoln, Y. S., \& Guba, E. G. (1989). Fourth Generation Evaluation. United States of America: Sage.

March, J. G., \& Shapira, Z. (1987). Managerial perspectives on risk and risk taking. Management Science, 22(11), 1404-1418. doi:10.1287/mnsc.33.11.1404

Massingham, P. (2010). Knowledge risk management: A framework. Journal of Knowledge Management, 14(3), 464-485. doi:10.1108/13673271011050166

Massingham, P. (2015). Knowledge Sharing: what works, what doesn't and why?: A Critical Systems Thinking Perspective. Systemic Practice and Action Research, 28(3), 197-228. doi:10.1007/s11213-014-9330-3

Massingham, P. (2016). Knowledge Accounts. Long Range Planning, 49(3), 409-425. doi:10.1016/j. lrp.2015.02.003

Massingham, P. (2018). Measuring the Impact of Knowledge Loss: An Empirical Longitudinal Study. Journal of Knowledge Management, 22(4), 721-758. doi:10.1108/JKM-08-2016-0338

Massingham, P., \& Al-Holaibi, M. (2017). Embedding Knowledge Management into Business Processes. Knowledge and Process Management, 24(1), 53-71. doi:10.1002/kpm.1534

Massingham, P., \& Diment, K. (2009). Organizational Commitment, Knowledge Management Interventions, and Learning Organization Capacity'? The Learning Organization, 16(2), 122-142. doi:10.1108/09696470910939206

Massingham, P., \& Massingham, R. (2014). Does Knowledge Management Produce Practical Outcomes. Journal of Knowledge Management, 18(2), 221-254. doi:10.1108/JKM-10-2013-0390 
Mouritsen, J., Larsen, H. T., \& Bukh, P. (2001). Intellectual capital and the 'capable firm': Narrating, visualising and numbering for managing knowledge. Accounting, Organizations and Society, 26(7), 735-762. doi:10.1016/ S0361-3682(01)00022-8

Neuman, W. L. (2006). Social Research Methods: Qualitative and Quantitative Approaches (6th ed.). Boston, MA: Pearson.

Nonaka, I., \& Takeuchi, H. (1995). The knowledge-creating company: How Japanese companies create the dynamics of innovation. New York: Oxford University Press.

Pomering, A. (2017). Marketing for Sustainability: Extending the conceptualisation of the marketing mix to drive value for individuals and society at large. Australasian Journal of Marketing, 25(2), 157-165. doi:10.1016/j. ausmj.2017.04.011

Raghu, T. S., \& Vinze, A. (2007). A business process context for Knowledge Management. Decision Support Systems, 43(3), 1062-1079. doi:10.1016/j.dss.2005.05.031

Ragsdell, G., Espinet, E. O., \& Norris, M. (2014). Knowledge management in the voluntary sector: A focus on sharing project know-how and expertise. Knowledge Management Research and Practice, 12(4), 351-361. doi:10.1057/kmrp.2013.21

Santos, F. M. (2012). A positive theory of social entrepreneurship. Journal of Business Ethics, 111(3), 335-351. doi:10.1007/s10551-012-1413-4

Sigala, M., \& Chalkiti, K. (2014). Investigating the exploitation of Web 2.0 for knowledge management in the Greek tourism industry: An utilisation-importance analysis. Computers in Human Behavior, 30(1), 800-812. doi:10.1016/j.chb.2013.05.032

Soto-Acosta, P., \& Cegarra-Navarro, J. G. (2016). New ICTs for Knowledge Management in Organizations. Journal of Knowledge Management, 20(3), 417-422. doi:10.1108/JKM-02-2016-0057

Stevens, R., Moray, N., \& Bruneel, J. (2015). The social and economic mission of social enterprises: Dimensions, measurement, validation, and relation. Entrepreneurship Theory and Practice, 39(5), 1051-1082. doi:10.1111/ etap. 12091

Thompson, A. J., Jr., Peteraf, M. A., Gamble, J. E., \& Strickland, A. J. (Eds.). (2016). Crafting \& Executing Strategy. The Quest for Competitive Advantage: Concepts \& Cases (20th ed.). Irwin, NY: McGraw-Hill.

Trevithick, P. (2008). Revisiting the knowledge base of social work: A framework for practice. British Journal of Social Work, 38(6), 1212-1237. doi:10.1093/bjsw/bcm026

Van der Aalst, W., \& van Hee, K. (2002). Workflow management: Models, Methods, and Systems. Cambridge, MA: MIT Press.

Villeneuve-Smith, F. (2011). “Fightback Britain”, State of Social Enterprise Survey 2011. London, UK: Social Enterprise.

Yin, R. K. (2014), Case Study Research: Design and Methods. Los Angeles, CA: SAGE. Retrieved from https:// agedcare.health.gov.au/aged-care-reform 
Peter Massingham is from the University of Wollongong's School of Management, Operations and Marketing within the Faculty of Business. Before joining the University in 1998, he was a management consultant, most recently with KPMG. He works with a range of Australian organisations on their business strategy, particularly focusing on knowledge management. Most recently he has completed a major research projects with the Australian Department of Defence on knowledge loss (2008-2013), Saudi Arabia Government on their research institutes (2008-2012), and a multi-disciplinary team on a project about sharing retirees' knowledge. He is currently working with a SSNFPO on their knowledge management

Rada Massingham works in the Accounting Discipline within the School of Business at Western Sydney University (Australia), where she is the Academic Course Advisor (International). She is a highly qualified accounting professional and researcher. Her experience has been in senior management positions within Australian industry, including BHP, Vinidex Tubemakers and Integral Energy. She is particularly interested in how accounting theory and practice can be used to help measure knowledge management, and extend existing business models, such as the Balanced Scorecard. Rada has completed her PhD on the Australian construction industry from a critical accounting theory perspective. She is currently working with a SSNFPO on the design of their knowledge management system to improve business processes and measure value.

Alan Pomering works in the research areas of: Marketing, Sustainability, Corporate Social Responsibility (CSR), and Corporate Marketing. He is internationally published in leading academic journals, business newspapers and magazines, and several international handbooks related to CSR. 